\title{
Peningkatan kesehatan gigi dan mulut melalui penerapan manajemen berbasis sekolah
}

\author{
Syahnur Said ${ }^{1}$, Nur Fadhilah Arifin ${ }^{2}$, Syamsiah Syam ${ }^{3}$ \\ ${ }^{1}$ Fakultas Ekonomi, Universitas Muslim Indonesia, Makassar \\ ${ }^{2,3}$ Fakultas Kedokteran Gigi, Universitas Muslim Indonesia, Makassar
}

\begin{abstract}
The Community Partnership Program (PKM) partners are SDN 96 Mannanti, Tellu Limpoe, Sinjai. The problem is: (1) The exchange rate of the rupiah against the US dollar is weakening which affects health costs (2) The high prevalence of dental caries which ranks fifth in the 10 most diseases (Data from the Mannanti Puskesmas Tellu Limpoe in 2017) (3). There is only one dentist in Mannanti village who only practices at the puskesmas. (4) Medical equipment especially dentistry tools at Mannanti puskesmas is limited. (5) Access to public transportation goes to Sinjai Hospital which is difficult and far enough ( $\pm 30 \mathrm{~km}$ distance and 60 minutes). (6) Public perception that dental examinations are expensive is also one of the reasons why someone is lazy to go to the dentist. The solutions offered from the PKM activities are: (a) Changing people's mindset from curative treatment shifting to promotive and preventive treatment so that the funds used are more minimum; (b) Implementation of SIKAPAMASE (SIkat gigi PAgi bersaMA di SEkolah) as an economical dental caries prevention program; (c) Application of topical fluor to students as an additional preventive measure to prevent cavities; (d) Guidance of teachers and parents as mediators of dental and oral health information to the community; (e) Healthy smile tooth ambassador competition for elementary students. The expected targets of the PKM activities are: (1) The caries status of SDN 96 Mannanti students reduced by 50\% measured through the DMF-T index (def-t) measured through the results of pre-test and post-test activities; (2) Increasing students' knowledge about how to maintain dental health is measured through the results of pre-test and post-test activities; (3) Our program products are in the form of human resources, it is expected that SDN 96 students can be mediators of dental and oral health information in the family, school and home environment; (4) Caries preventive guidance booklet (5) Ambassador of healthy teeth. (6) SIKAPAMASE (SIkat gigi PAgi bersaMA di SEkolah) as an innovative program at the Mannanti health center that is carried out continuously.
\end{abstract}

Keywords: bulk toothbrushes at school, ambassador for healthy teeth, innovative program Sikapamase

\section{PENDAhuluan}

Pelaksanaan Riskesdas 2018 akan dilaksanakan secara terintegrasi dengan Survei Sosial Ekonomi Nasional (Susenas) BPS yang salah satu tujuannya adalah agar penduduk dengan mudah mendapatkan perawatan kesehatan secara menyeluruh tanpa mengeluarkan biaya yang banyak (Badan Litbangkes, 2013; Kemenkes RI, 2013).

Sementara disisi lain, pelemahan rupiah terhadap dolar bisa menjadikan biaya kesehatan semakin mahal. Nilai tukar rupiah terhadap dollar AS semakin melemah dan membuat kekhawatiran bagi banyak pihak. Nilai kurs rupiah Oktober 2018 mencapai angka Rp. 15.145 per dollas AS. Melemahnya nilai tukar rupiah terhadap dollar tentunya akan membawa dampak yang tidak baik bagi perekonomian Indonesia dan berpengaruh pada naiknya biaya kesehatan. Pasalnya, industri farmasi harus bergerak sendiri tanpa adanya dukungan dari pemerintah dalam bentuk insentif ataupun keringanan pajak. Maka dari itu, jangan heran apabila biaya untuk bisa sehat menjadi lebih mahal.

Desa Mannanti Kecamatan Tellu Limpoe Kabupaten Sinjai merupakan salah satu desa binaan yayasan wakaf UMI. Jarak Desa Mannanti dari Kota Makassar sekitar $200 \mathrm{~km}$ atau sekitar 5 jam bila ditempuh dengan kendaraan. Jarak dari desa ke ibu kota kabupaten sekitar 25 km (BPS Kabupaten Sinjai, 2018). Di daerah ini terdapat 1 Puskesmas yang memiliki satu orang dokter gigi saja dan hanya berpraktek selama jam dinas puskesmas. Peralatan medis khususnya alat-alat kedokteran gigi pada puskesmas tersebut masih sangat terbatas, dilain pihak jika penduduk 
menginginkan SDM, sarana, dan prasana yang memadai, mereka harus ke daerah perkotaan yang jaraknya cukup jauh dari desa sehingga mereka harus mengeluarkan dana lebih untuk hal tersebut. Ditambah lagi persepsi masyarakat biaya periksa kedokter gigi itu mahal juga menjadi salah satu alasan penyebab seseorang malas ke dokter gigi.

Data yang diperoleh dari Puskesmas Mannanti tahun 2017 prevalensi karies cukup tinggi, menduduki urutan ke 5 dalam 10 penyakit terbanyak setelah tonsillitis, gastritis, Influensa dan hipertensi. Tingginya angka kejadian karies disebabkan oleh terabaikannya kebersihan gigi dan mulut, cara menyikat gigi yang kurang benar, serta pola makan yang tidak sehat.Pada saat menyikat gigi biasanya anak-anak kurang memerhatikan penggunaan sikat gigi yang benar, tidak sesuai dengan ukuran gigi anak. dan menyikat gigi pada waktu yang salah menyebabkan kurang efektif dalam pembersihan gigi. Siswa Sekolah Dasar (SD) memiliki kebisaan mengkonsumsi makanan jajanan yang bersifat kariogenik, seperti makanan manis, lengket. Makanan kariogenik mempunyai kecenderungan melekat pada permukaan gigi sehingga terjadi karies (Puskesmas Mannanti, 2017).

Pencegahan penyakit pada gigi anak masih luput dari perhatian orang tua. Karies pada gigi anak sering dianggap hal yang biasa saja sehingga orang tua sering kali mengabaikan kondisi kesehatan gigi anaknya meskipun memiliki efek besar terhadap perkembangan fisik serta mental anak. Gigi pada anak merupakan menentukan pertumbuhan dan perkembangan rongga mulut karena gigi susu anak akan menentukan gigi tetap dari anak tersebut. Bila seorang anak memiliki gigi yang tidak sehat menyebabkan anak tersebut kesulitan dalam mencerna makanan sehingga anak mengalami gangguan terhadap proses pertumbuhannya, akibatnya anak menjadi sering sakit yang dapat mengganggu kehadiran serta performa mereka disekolah.

Peningkatan derajat kesehatan penduduk dapat dicapai secara lebih mudah dan lebih murah melalui upaya promotif-preventif dan penanggulangan risiko daripada upaya kuratif. Dahulu tanggung jawab kesehatan diserahkan sepenuhnya oleh masyarakat kepada para pelaku pelayanan medis kini harus menjadi tanggung jawab pemeliharaan kesehatan kepada individu dan masyarakat. Upaya promotif-preventif dan meningkatkan kesehatan lingkungan tidak mungkin hanya dilakukan oleh sektor kesehatan, tetapi justru diperlukan kerja sama lintas sektor.

Oleh karena itu diperlukan satu konsep dan pemikiran yang mampumengakomodir berbagai wacana dan fenomena tentang dunia kesehatan gigi dan mulut. Dengandemikian diperlukan satu metode pengelolaan yang menyeluruh. Metode pengelolaan inilah yang dikenal dengan manajemen berbasis sekolah dalam peningkatan kesehatan gigi dan mulut.

\section{METODE PELAKSANAAN}

\section{A. Tahap Persiapan}

Langkah awal yang kami lakukan saat pengabdian yaitu melakukan pertemuan konsolidasi bersama mitra dan mengundang stakeholder terkait untuk mensosialisasikan rencana kegiatan yang akan dilaksanakan.

\section{B. Pelaksanaan Program Pengabdian}

Kegiatan pertama yang kami lakukan pada saat pengabdian kami melakukan pretest pengetahan mengenai kesehatan gigi kepada siswa SDN 96 Mannanti serta melakukan pemeriksaan Status Karies siswa SDN 96 dengan menggunakan indeks DMF-T (def-t) dibantu oleh petugas kesehatan puskesmas Sinjai.

Mengubah perilaku anak-anak tentang kesehatan gigi dan mulut bukanlah hal yang mudah, tak cukup dilakukan hanya dengan penyuluhan saja, oleh karena itu kami melakukan program SIKAPAMASE (Sikat Gigi Pagi bersama di Sekolah). Sebagai upaya tambahan kami melakukan pengulasan fluor secara topical. Pengulasan Fluor secara topikal mampu mengurangi kerusakan email oleh asam yang dapat menghambat karies gigi.

\section{Tahap Monitoring dan Evaluasi}

Tahap monitoring hasil kegiatan PKM ini kami melakukan penilaian post test pengetahuan anak 
mengenai kesehatan gigi dan mulut serta pemeriksaan status karies setelah kegiatan. Kami melakukan lomba duta gigi sehat untuk siswa-siswi serta lomba kader kesehatan gigi. Guru dan kader kesehatan diharapkan sebagai mediator informasi kesehatan gigi dan mulut pada masyarakat, dan siswa-siswi dapat menjadi mediator informasi kesehatan gigi dan mulut di lingkungan keluarga, sekolah dan lingkungan rumahnya. Untuk tahap keberlanjutannya kami akan bekerjasama dengan pihak sekolah dan PKM Mannanti untuk mencanangkan kegiatan SIKAPAMASE-TA sebagai program inovatif di sekolah dan akan dikontrol sekali sebulan oleh tim.

\section{HASIL DAN PEMBAHASAN}

\section{A. Kunjungan Sosialisasi dan Pelatihan}

Pada pelaksanaan Program Kemitraan Masyarakat (PKM), Tim pelaksana melakukan kunjungan ke lokasi mitra sebanyak empat kali. Kunjungan pertama dilakukan pada Hari Senin tanggal 22 April 2019 untuk melakukan observasi awal kondisi yang terjadi pada mitra (SDN 96 Mannati) terkait dengan masalah kesehatan gigi dan mulut anak. Jumlah siswa sebanyak 169 siswa.

\section{B. Implementasi}

Kunjungan kedua dilakukan pada Hari Kamis tanggal 18 Mei 2019, pada kunjungan ini tim melakukan empat kegiatan:

1. Tim melakukan pretest kepada siswa SDN 96 Mannati dengan membagikan kuisioner yang berisi tentang tingkat pengetahuan siswa mengenai kesehatan gigi dan mulut;

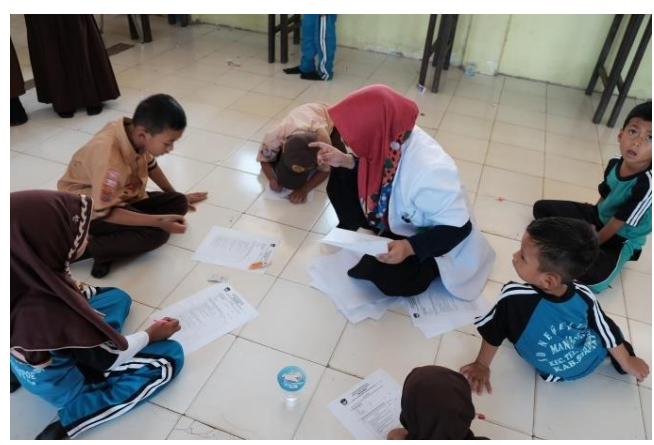

Gambar 1. Pembagian kuesioner pengetahuan sebelum kegiatan PKM
2. Melakukan penyuluhan tentang kesehatan gigi dan mulut. Penyuluhan kesahatan gigi dan mulut dilakukan agar mitra mendapatkan edukasi dan pengetahuan mengenai kesehatan gigi dan mulut. sehingga perubahan mindset masyarakat khususnya siswa-siswi SDN 96 Mannanti dapat dengan mudah terjadi dari tindakan kuratif beralih ke tindakan promotif dan preventif, dengan demikian dana yang dikeluarkan untuk keperluan kesehatan gigi dan mulut lebih ekonomis.

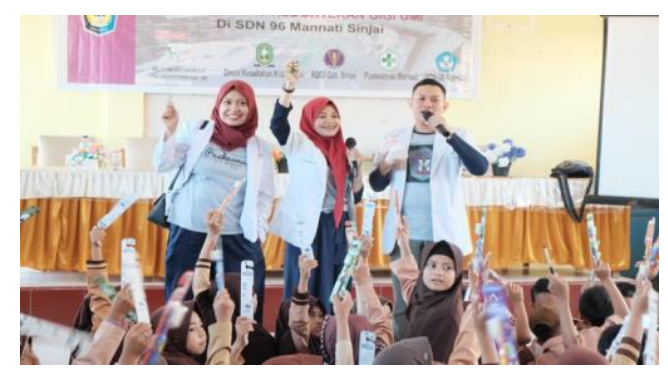

Gambar 2. Penyuluhan kesehatan gigi

3. Melakukan kegiatan sikat gigi bersama di sekolah. Kegiatan sikat gigi massal melalui program SIKAPAMASE (SIkat gigi PAgi bersaMA di SEkolah), kegiatan ini mempraktekkan cara sikat gigi yang baik, dan diharapkan dapat berjalan secara kontinyu sebelum pembelajaran dimulai.

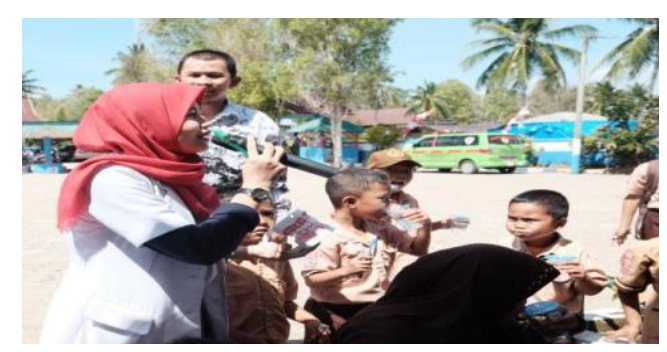

Gambar 3. Sikat gigi pagi bersama di sekolah

4. Melakukan screening pemeriksaan kesehatan gigi dan mulut. Sebelum kegiatan dimulai dilakukan pemeriksaan gigi siswa dengan menggunakan form WHO menilai status karies siswa dengan menggunakan indeks DMF-T. 


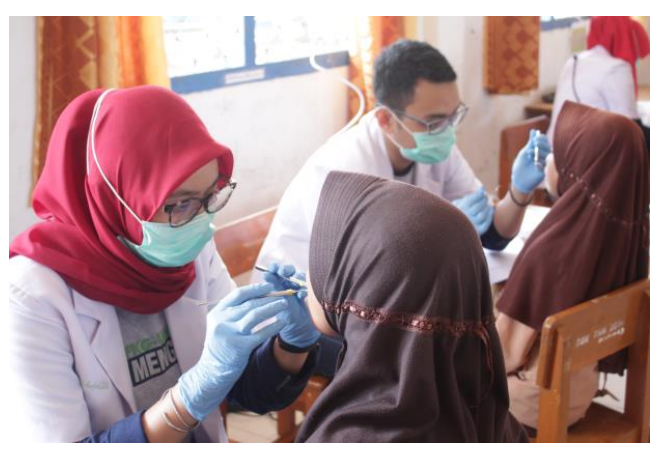

Gambar 4. Screening kesehatan gigi sebelum implementasi kegiatan PKM

\section{Tahap Monitoring \& Evaluasi}

Kunjungan ketiga dilakukan pada hari Selasa 23 Juli 2019 bertepatan dengan hari anak nasional

1. Pada kunjungan ini tim melakukan follow up kegiatan sikat gigi bersama disekolah yang telah diadakan pada kunjungan sebelumnya, pembagian kuisioner post test mengenai pengetahuan kesehatan gigi anak setelah dilakukan kegiatan pengabdian.

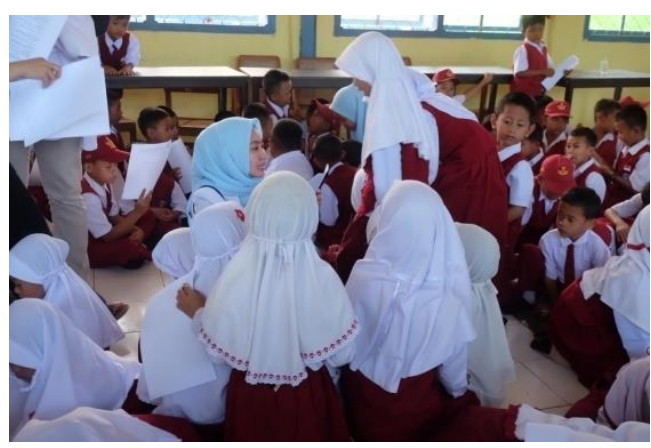

Gambar 5. Pembagian kuesioner setelah dilakukan kegiatan PKM

Tabel 1. Perbedaan tingkat pengetahuan sebelum dan sesudah kegiatan PKM

\begin{tabular}{ccccc}
\hline Pengetahuan & Mean & n & $\begin{array}{c}\text { Standar } \\
\text { Deviasi }\end{array}$ & $\boldsymbol{p}$ \\
\hline Pre Test & 2,44 & 134 & 0,778 & 0,000 \\
Post Test & 2,75 & 134 & & \\
\hline
\end{tabular}

Tabel 1 menunjukkan bahwa terjadi peningkatan pengetahuan antara sebelum dan sesudah mengenai cara menjaga kesehatan gigi dan mulut dalam mencegah karies gigi pada siswa siswi SDN 96 Mannanti, Kecamatan Tellu Limpoe, Kabupaten Sinjai dengan nilai $p$ value 0,000 .
2. Pemeriksaan evaluasi kesehatan gigi dengan mengukur status karies dengan indeks DMFT. Dari total 162 siswa hanya terdapat 134 siswa yang memenuhi kriteria sampel yaitu memiliki data yang lengkap (terdapat data pemeriksaan kesehatan gigi sebelum dan sesudah kegiatan PKM serta telah mengisi kuesioner tingkat pengetahuan kesehatan gigi sebelum dan sesudah kegiatan PKM).

Tabel 2. Perbedaan DMF-T sebelum dan setelah kegiatan PKM

\begin{tabular}{cccc}
\hline DMF-T & Sebelum & Setelah & P VALUE \\
\hline $\mathrm{D}$ & 768 & 679 & 0,000 \\
\hline $\mathrm{M}$ & 57 & 57 & 1,000 \\
\hline $\mathrm{F}$ & 27 & 116 & 0,000 \\
\hline
\end{tabular}

Tabel 2 menunjukkan terdapat perbedaan yang signifikan sebelum dan sesudah pada kasus Decay dan Filling dengan nilai $p$ value 0,000, sedangkan pada kasus Missing menunjukkan tidak terdapat perbedaan yang signifikan dengan nilai $p$ value 1,000 .

3. Pengaplikasian TAF bagi siswa-siswi yang masuk indikasi adalah yang telah melewati proses screening pada pemeriksaan kesehatan gigi dan mulut yang sebelumnya telah dilakukan oleh tim dan bebas karies. Upaya aplikasi topical fluor dapat mencegah kejadian atau peningkatan karies pada siswa-siswi SDN 96 Mannanti.

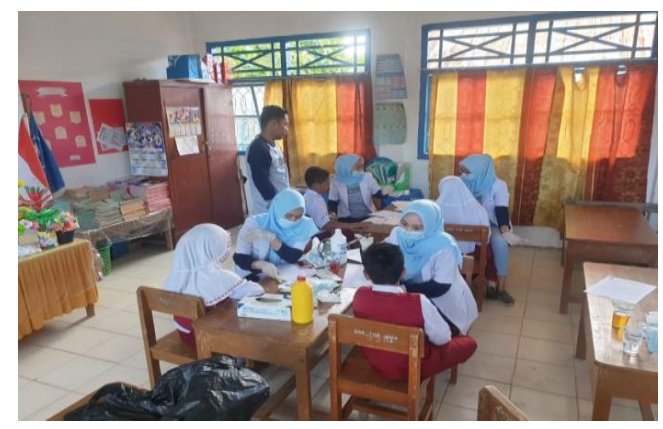

Gambar 6. Foto pemeriksaan evaluasi kesehatan gigi setelah kegiatan PKM dan Pengaplikasian TAF

4. Pada kunjungan ketiga ini juga dilakukan bimbingan teknis peran orang tua dan guru dalam peningkatan kesehatan gigi dan mulut 
anak. Hal ini ini dilakukan, mengingat kesehatan gigi dan mulut anak sangat bergantung pada support, bimbingan, dan pengawasan orang tua serta guru yang bertindak sebagai orang tua disekolah.

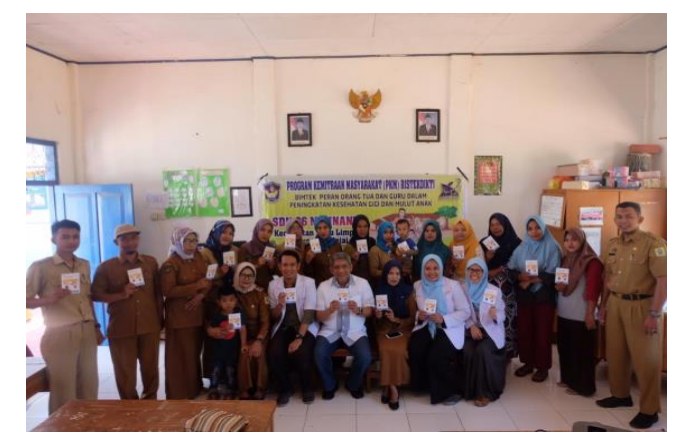

Gambar 7. Foto kegiatan bimtek pada orang tua dan guru

5. Selanjutnya tim pengabdian melakukan lomba duta gigi sehat bagi siswa yang memiliki gigi sehat (free caries). Kegiatan terakhir pada kunjungan ini adalah tim melakukan pelatihan penyuluh kesehatan gigi kepada siswa-siswi SDN 96 Mannanti sehingga baik orang tua, guru, maupun siswa siswi dapat berperan sebagai penyuluh kesehatan gigi dari keluarga, sekolah hingga ke masyarakat luas.
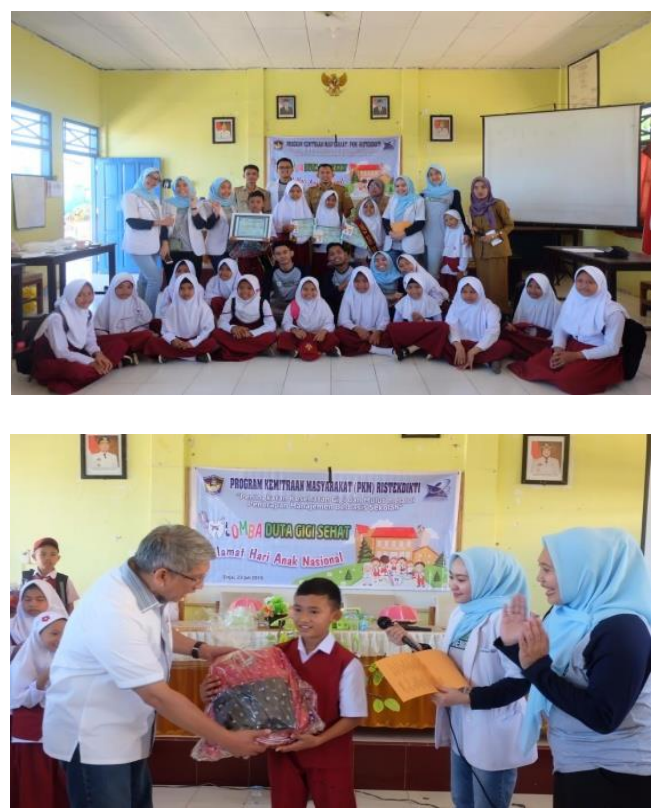

Gambar 8. Foto duta gigi sehat

\section{KESIMPULAN}

Dengan dilaksanakannya upaya peningkatan kesehatan gigi dan mulut melalui penerapan manajemen berbasis sekolah di SDN 96 Mannanti Kecamatan Tellu Limpoe, Kabupaten Sinjai dapat meningkatkan pengetahuan siswa tentang kesehatan gigi dan mulut serta dapat menurunkan prevalensi karies dan tentunya biaya untuk bisa sehat tidak membutuhkan dana yang besar (lebih ekonomis).

Dari kegiatan pengabdian yang dilakukan diharapkan Dukungan masyarakat,pihak sekolah, pemerintah setempat dan stakeholder terkait sangat dibutuhkan untuk keberlangsungan program secara berkesinambungan.

\section{UCAPAN TERIMA KASIH}

Ucapan terimakasih disampaikan kepada Direktorat Jendral Pendidikan Tinggi yang telah memberikan hibah. Selanjutnya ucapan terima kasih disampaikan pula kepada bapak Rektor dan Ketua Lembaga Pengabdian kepada Masyarakat UMI atas arahan dan pembinaanya selama proses kegiatan Pengabdian Masyarakat berlangsung. Demikian pula ucapan terimakasih disampaikan kepada Dinas Kesehatan dan PDGI Kabupaten Sinjai Provinsi Sulawesi Selatan, yang telah memberi mengawal dan mendukung kegiatan yang kami laksanakan.

\section{DAFTAR PUSTAKA}

Badan Litbangkes. Laporan Riset Kesehatan Dasar 2013 Jakarta: Lembaga Penerbit Badan Litbangkes; 2014Badan Penelitian dan Pengembangan.

BPS Kabupaten Sinjai. Kecamatan Tellulimpoe dalam Angka 2018.

Kemenkes RI., Riset Kesehatan Dasar 2013, Badan Penelitian Pengembangan Kesehatan, Jakarta, 2013. 